\title{
What is the Role of Social Work in China? A Multi-Dimensional Analysis
}

\author{
Jieru Bai
}

\begin{abstract}
This article analyzes the role of social work in the context of the special political, economic, cultural, and historical background in China. A historical perspective is used to understand the evolution of the Chinese welfare system and explain the timing of reintroducing the social work profession. A pluralistic perspective is adopted to define social work relating to different stakeholders in social welfare and services. The government starts to diminish its role as a direct service provider. The traditional family and community have less capacity to take care of people. Yet, the social work profession is not ready to take over. Finally, a social development perspective is used to illustrate why economic growth is prioritized by the Chinese government and social work as profession is supposed to work to promote social stability and prosperity. Implications for social work research and practice are discussed.
\end{abstract}

Keywords: China, pluralistic, social development, policy

Through the past few decades, China has experienced fundamental economic, political, and social changes. On the one side, China has achieved significant improvements in poverty alleviation and social development (Chi, 2005). On the other hand, China is facing numerous new challenges due to rapid social change, including poverty, income disparities, family breakdown, rural-urban migration, unemployment, underemployment, criminality, housing, an aging population, child labor, public health, and environmental pollution (Leung, 2007; Tsang \& Yan, 2001). In order to maintain the economic success and achieve wealth and prosperity, the Chinese government has implemented corresponding welfare reform to remedy social problems, avoid social unrest (Guan, 2003), and maintain social stability (Chi, 2005). Development and professionalization of social work was strongly advocated by top Chinese leaders and perceived as the most important theme in the welfare reform (Xiong \& Wang, 2007).

In 1986, social work was officially recognized as a university discipline and four universities started to provide social work programs. Within the following twenty years, the number of social work programs increased from 20 in 1994 to more than 300 in 2011 (personal communication, Sibin Wang, the current president of the China Association of Social Work Education, December, 2011). After the new millennium, the government has selected large, metropolitan cities as experiments, such as Shanghai, Shenzhen, and Beijing, to develop local social service delivery systems and social work teams (Hung, $\mathrm{Ng}$, \& Fung, 2010; Leung, 2007). In 2003, the government of Shanghai issued Temporary Measures of Qualifications for Social Workers Registration and tried some experimental projects of employing professional social workers in hospitals, community centers, and schools. By 2010, there were more than 1,500 people registered as social workers (Shanghai Civil Affairs Bureau, 2010). Those social workers have played an important role in providing services for juvenile delinquents, the elderly, and people with

Jieru Bai, Ph.D., is an Assistant Professor in the Grace Abbot School of Social Work at the University of Nebraska at Omaha.

Copyright (C) 2014 Advances in Social Work Vol. 15 No. 2 (Fall 2014), 495-506 
substance abuse problems (Xiong \& Wang, 2007). Following the steps of Shanghai, the government of Shenzhen developed an integrated system in which the government purchased services from independent social service agencies (Hung et al., 2010). The Shenzhen Bureau of Civil Affairs provides funding and helps to develop nongovernmental social work organizations which hire social workers and provide direct services.

The experiences of experimental cities strengthened the government's determination to promote social work as a profession for the whole country. In recent years, the government made great efforts in legislation and provided legal support in the professionalization of social work. In 2004, the Ministry of Labor and Social Security issued Regulations on the Occupationalization of Social Workers. In 2006, the Ministry of Civil Affairs and the Ministry of Personnel issued Temporary Regulations on the Social Workers Occupational Standard System, by which the government officially recognized social work as a profession. Right after that, the Ministry of Civil Affairs and the Ministry of Personnel published Regulations on the Professional Certification for Assistant Social Workers and Social Workers, which defined different positions and corresponding requirements of the new profession. The experiences also demonstrated the importance of the government's support in the successful, experimental cities.

As a socialist country, the Chinese government plays a strong and directive role in the development of social welfare as well as the social work profession (Tsang \& Yan, 2001). Many Chinese scholars appreciate that it is a golden chance for the development of professional social work in China. However, others criticize that although the term "social work profession" has suddenly become popular and frequently appears in various government reports, "a widely agreed definition of what social work is and what social workers do is missing" (Xiong \& Wang, 2007, p. 568).

This article analyzes the role of social work in the context of the special political, economic, cultural, and historical background in China. A multi-dimensional model is used to analyze why the Chinese government is determined to develop social work contemporarily, and how to define social work as a profession in the Chinese welfare system. Implications for social work research and practice are discussed.

\section{A Multi-Dimensional Model}

In order to explain the timing of the professionalization of social work, a historical perspective is used to understand the evolution of the Chinese welfare system and social work profession. In consideration of the vastness and complexity of the social problems in China, a pluralistic perspective is adopted to define social work relating to different stakeholders in social welfare and services, including the state sector, the voluntary sector, the informal sector, and the commercial sector. Moreover, China is still a developing country and economic growth is its highest priority. There is a consensus that the current policy is directed to maintain social stability in order to achieve wealth and prosperity for the country. The major assignment for the social work profession is to remedy social problems caused by economic reform (Xiong \& Wang, 2007), which reflects the political-economic perspective in social policy. This article combines these three 
perspectives and proposes a multi-dimensional model (see Figure 1) to explain the role of social work in China.

Figure 1. Multi-Dimensional Model of Social Work in China

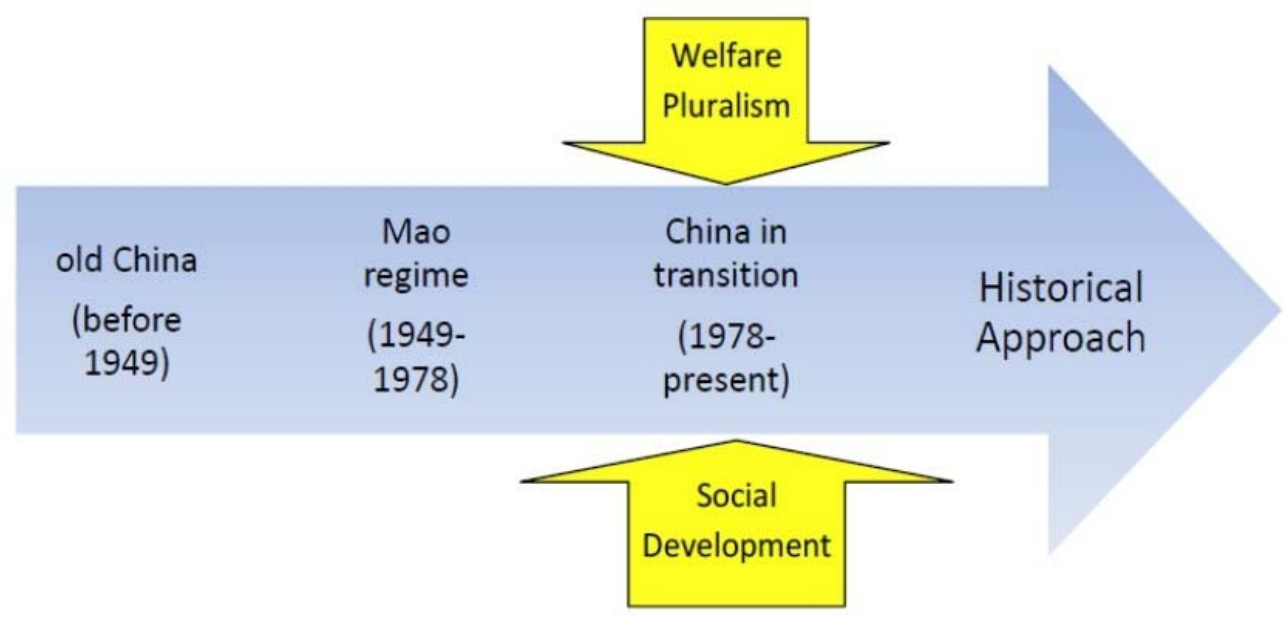

\section{The Historical Perspective}

\section{Old China: Before 1949}

Before the People's Republic of China (New China) was founded in 1949, China had been a feudal society for nearly three thousand years. Confucianism was, and still is, the dominant belief system in China. It provided a foundation for social welfare ideology in Chinese culture (Hutchings \& Taylor, 2007). Core values of Confucianism include reciprocity, filial piety, loyalty to one's family, and consensus and harmony (Chung, 1992). Confucianism encourages mutual help because of the individual's responsibility for the collective good (Chan \& Tsui, 1997). Individuals and families were the primary caregivers. Social provisions from the state were limited to famine relief on an ad hoc basis (Chan \& Tsui, 1997). In addition, Buddhist temples were the major charitable entities. This is similar to the role of churches in western societies before social work was developed.

Social work was absent from Chinese history until the 1920s, when it was first introduced to China by western missionaries. However, at that time, China was invaded by western countries and Japan and then trapped in civil war. Although there were approximately 20 social work-related education programs before the People's Republic of China was established in 1949 (Yan \& Tsang, 2005), social work was not able to develop in the society.

\section{Communist China: 1949-1978}

After the Communist Party took over in 1949, a centrally-planned economy was established. The central government took the responsibility of providing social welfare to 
the whole Chinese society (Tsang \& Yan, 2001). In urban areas, citizens enjoyed employment-based social welfare. "Danwei", or work units, provided comprehensive social services for their employees, including housing, food, education, child care, health care, income protection, and old age pensions (Leung \& Nann, 1995). In rural areas, social welfare was delivered by production teams (Mok, 1983). However, there was a huge gap between welfare in urban areas and rural areas. Rural welfare services were relatively undeveloped due to limited resources.

Within this period, all social sciences, including sociology and social work courses, were eliminated from the universities during the "restructuring of institutions of higher learning" (Yuen-Tsang \& Wang, 2002, p. 376). The underlying rationale was that social welfare was a by-product of capitalism to remedy social ills, while the socialist state itself was a social welfare agency (Mok, 1983). Social work was removed before having any chance to develop.

\section{China in Transition: 1978-Present}

In 1978, the Chinese government decided to shift the focus of national policy from political debate to economic development. The government initiated the transition from a planned economy towards a market economy and opened the door of China to the world. Within those political and economic transformations, the welfare system of China also underwent profound changes.

In 1983, the collective system was formally ended. During the 1990s, many stateowned enterprises were dissolved. Individuals were no longer permanently protected by the collectives. The comprehensive employment-based welfare was terminated, but no substitute welfare system has been established yet. As a result, many people were left out in the welfare transition. They no longer receive free housing, education, and medical care from the government. Instead, they have to pay for everything out of their own pockets. Unfortunately, this is challenging for many people.

In facing those new social problems, the Chinese government tried to engage various resources and encouraged localized services (Leung \& Nann, 1995). In the late 1980s, the Chinese government brought up the concept of "large society and small government." The government started to reduce its responsibility in providing social welfare and tried to promote the "socialization" of social services. Private, quasi-government, and nongovernmental sectors were encouraged to share the responsibility for welfare service provision (Leung, 2007). The government's diminishing role in welfare provision combined with increasing social needs imposed great pressure on the social welfare system (Xiong \& Wang, 2007). As a result, the Chinese government decided to reintroduce social work. The government expected the new profession to provide comprehensive services and help remedy social ills. Social work programs expanded rapidly with the support from the government.

\section{Welfare Pluralism Perspective}

Welfare pluralism, also referred as "mixed economy of welfare," contends that there are four sectors involved in the production and delivery of welfare. They are the state 
sector, the commercial sector, the non-profit or voluntary sector, and the informal sector (Gilbert, 2008). Currently in China, although most social services are directly operated by the state, a multiple-intervention system is emerging. People are encouraged to seek help from informal and semi-formal system (Smith, 2003).

\section{The State Sector}

Social welfare in China is provided by various organizations under the leadership of the central government. The most important agencies are the Ministry of Civil Affairs and the Ministry of Labor and Social Security. Civil affairs work has been well established within each level of government and is considered as social work with Chinese characteristics (Wang, 2011). At present, there are nearly 500,000 people working in the civil affairs system (Li, Huang, \& Han, 2012). Instead of being direct service providers, the government is now focusing more on policy, legislation, management, and financial support. The welfare delivery system is decentralized, and community-based services are developed. However, most of the staff members hired in civil affairs organizations do not have a social work background. They usually perceive their work as administrative and executive duties.

Wang (2011) defined the "Embedded Model" of social work development in China. Because the civil affairs system has been functioning since 1978, social work as a new profession has to strive for its place both within and outside the historical structure. Social work educators like Wang have advocated for embedding social work within the civil affairs system and gradually transferring the civil affairs work into professional social services. In recent years, many social work students have been sent to national and local Bureaus of Civil Affairs for their practicum experiences. Working in the civil affairs system is one of the few jobs related to social work that students can find in China (Wong \& Pearson, 2007; Yan, Ge, Cheng, \& Tsang, 2009). However, this model has triggered the argument about who should take the lead: staff members without professional training but who understand the services or social workers with professional training but having little experience in the system? The Embedded Model also echoes the strong political tradition in Chinese social welfare system.

\section{The Voluntary Sector}

During the 1990s, many local and international NGOs (non-governmental organizations) and NPOs (non-profit organizations) emerged in China. The number of NGOs registered in the Ministry of Civil Affairs increased from 5,901 in 1999 to 381,361 by the third quarter of 2008 (Ministry of Civil Affairs, 2008). Those newly emerged NGOs played more and more important roles in producing and delivering social services.

Before this period, the Chinese government held a very skeptical attitude toward the development of NGOs. Now, the government allows much more room for the development of NGOs. Especially during the Sichuan earthquake in 2008, the government demonstrated unprecedented flexibility toward NGOs because of their contributions in crisis intervention and post-disaster reconstruction. Currently, the government is working actively on the legislation and standardization of NGOs. NGOs 
are expected to replace the welfare services which the government no longer provides. However, the government does not provide tangible support for the NGOs beyond tax incentives (Wong, 2008). As a result, numerous NGOs are facing great difficulties in finding stable funding sources, establishing efficient management, and recruiting professional workers.

Though growing rapidly, the function of the NGOs as service providers is limited (Hutchings \& Taylor, 2007; Tsang \& Yan, 2001). Due to the political environment, it is hard for grassroots NGOs to achieve true independence (Wong, 2008). The quality of the services from grassroots NGOs varies greatly depending on what resources they can get in the society. Some well-functioning NGOs are actually affiliated with governmental organizations, or transformed from previous government branches. Thus, they have adequate funding sources and other support from the government. However, they do not function independently as the third sector.

\section{The Informal Sector}

Informal care refers to the help received from family, friends, neighbors, and other non-statutory sources (Gilbert, 2008). Informal care and family obligations are valued in Chinese tradition and are still important principles of the contemporary welfare system (Chan \& Tsui, 1997). The government uses legislation to enforce the family's responsibility to take care of individuals and an individual's obligation to the family (Leung, 2001). However, in modern society, the capacity of Chinese families to provide care is seriously deteriorating (Leung \& Wong, 2002). Because of the one-child policy, most families are now nuclear families. The family size is decreasing while the divorce rate is increasing, which means there are fewer people in stable family relationships that share the responsibility of caregiving. What is more devastating, due to the urbanization, many rural residents have left their land and migrated to urban areas to make money, while their elder parents and young children are left behind to take care of themselves (Shang, $\mathrm{Wu}, \& \mathrm{Wu}, 2005$ ). This phenomenon seriously threatens the traditional Chinese family values and undermines the family's capacity as the primary care provider.

The rapid change in family structure results in urgent needs for professional services, especially for elderly people. It is anticipated that the portion of elderly people (age 65 and above) in the population will increase from $8 \%$ in 2010 , to $16 \%$ in 2030 and $24 \%$ in 2050 (Jackson, 2011). The growing aging population will overwhelm the traditional care model for elderly people, where adult children take care of their elderly parents. Using professional services will be inevitable for Chinese families. The professional services will compensate the weakening roles of family as the primary care provider. However, this change will challenge Chinese people's values about family and filial piety, which is fundamental in Confucianism. Some people believe that sending elderly parents to nursing homes is abandoning them. Social work as a new profession will have to cope with those negative attitudes and help people transform their values. 


\section{The Commercial Sector}

The commercial sector of the welfare system in China is not well developed yet. From the middle of the 1990s, the Chinese government has been trying to commercialize higher education and the medical care system, but has encountered great resistance. People have been very dissatisfied with the booming prices. Many people from urban poor and rural families cannot afford higher education and medical care. After admitting the failure of the medical care system reform in 2006, the Chinese government is now promoting a social insurance system to the whole society. In urban areas, employers are mandated to purchase medical insurance for employees. In rural areas, the government has established a new insurance system named "New Cooperative Medical Scheme" (NCMS). The system is co-financed by rural residents (a premium of RMB 60/USD 10 per year), the central government, and each level of local government. Rural residents get reimbursement for inpatient services and outpatient services for severe medical problems. As of now, the majority of rural residents in China participate in the NCMS.

Meanwhile, because of the economic reform and policy change, there are many more private hospitals, schools, and nursing homes in China. In 2013, the Chinese government started to allow for-profit services for elderly people and people with disabilities. Chan and Tsui (1997) argued that the private sector will play a greater role in meeting social needs, particularly for those who have become rich thanks to economic reform.

The welfare pluralism perspective provides a holistic overview of the welfare system in China. However, it is easy to isolate each part and neglect the interaction among different sectors. In a socialist country, the influence of the government is prevailing. None of the other sectors can totally be independent of the government. Thus, it is important to consider welfare pluralism under the centralized political system in China.

\section{Social Development Perspective}

The social development perspective broadens the traditional view of Western social welfare by including economic development (Lowe, 1995). It contends that economic development is a way of promoting the well-being of the whole population and achieving social goals (Midgley \& Sherraden, 2008). The social development perspective is particularly popular in developing countries, where a comprehensive social welfare system is not available. Economic development is vital for developing countries to build up a social welfare system and enhance the overall well-being of the society.

As a developing country, China has prioritized economic development as the most significant national task since 1978. After nearly 30 years of economic reform and opening up to the outside world, China has achieved remarkable economic development. The living standard of its citizens has been greatly improved. However, the achievement is dramatically uneven between rural and urban areas, between eastern coastal and inland provinces, and among different populations (Chi, 2005). China's Gini coefficient, which measures the disparity between rich and poor, increased from 28.2 in 1981 to 38.8 in 1995 and 47.4 in 2012 (Atinc and World Bank, 1997; National Bureau of Statistics of the People's Republic of China, 2013). Social inequality and class divisions have become more and more severe. 
In the face of those critical social problems and potential social conflicts, the Chinese government has shifted its policy from focusing only on economic growth to balancing economic development and social development. Stability is considered the premise of economic development. Building a socialist harmonious society is proposed by the former President Hu Jingtao as the national goal of contemporary China. The government has made great efforts to improve the social welfare system. Rebuilding social work as a profession is one of the most important agendas. There is a consensus between the government and social work scholars that the mission of social work in China is to fix social problems, maintain social stability, and support economic development. For example, Chi (2005) contends that the main objective of social welfare is to provide basic benefits to maintain social stability. Guan (2003) maintains that the primary task of social welfare is to provide a basic safety net, avoid social unrest, and make China more competitive in the world economy. The Chinese social workers are very clear about their roles as problem-solvers within the existing political system.

The social development perspective was critiqued for overemphasizing economic participation while neglecting the real hardships of disadvantaged groups. Many developing countries endorsing a social development perspective have experienced situations similar to that in China. The benefits of growth are experienced by privileged groups, while the major burden of growth is imposed on poor people (Midgley \& Sherraden, 2008). Tang (1996) argued that social work and social welfare are marginalized in developing countries, and the expenditure on social programs is limited to a minimum part in economic development.

\section{Discussion and Implications}

The multi-dimensional model of this article provides a comprehensive analysis of the welfare system and the role of social work in China. The historical analysis explains how Chinese welfare systems evolved into the current situation and why social work has received more attention now. Through a welfare pluralism lens, it is explicit that social work in China will have a greater potential for development. The government sector will be the main source of job positions for future social workers. Meanwhile, the increasing grassroots NGOs and private service agents will have an urgent need for professional social workers. The informal sector will also require professional intervention to compensate for the eroding capacity of families as care providers. The social development perspective helps define the role of social work as a problem-solver within an existing political system. The task of social work is to remedy social problems, maintain social stability, and sustain economic development. Only with the clear understanding of the professional role and task can Chinese social workers develop indigenized intervention strategies and function appropriately in a socialist system.

Currently, the development of social work in China is facing many challenges. The whole society has encountered many new social problems which they have never experienced before. Also in a developing country, resources are particularly limited. Chinese social workers have to develop the new profession and accomplish its mission in a cost-effective way. Social work, as a new profession, is not yet well recognized in Chinese society. Not many Chinese people know what social work is and most people 
cannot differentiate social workers from volunteers or social work from charity activities (Tong, 2007). Localizing social work and making the profession compatible with Chinese cultural values are critical issues for social work pioneers.

Social work education in China is also confronted with numerous problems. Many social work programs do not have an independent status in universities but often are affiliated with sociology, public administration, or political science (Bai \& Daley, 2014). Most social work programs lack professional social work educators and practicum supervisors. Of even more concern, a social work job market is nearly non-existent in China (Sha, Wong, Lou, Pearson, \& Gu, 2012; Yan et al., 2009). Yan and her colleagues (2009) interviewed 31 social work students and only five of them reported that they would try to look for social work related jobs. Sha and his colleagues (2012) surveyed 1,331 social work students in Beijing and Shanghai. They found that fewer than $40 \%$ of the students expect to perform any social work activities in the first five years after graduation. The jobless reality has led to a severe waste of social work education in China.

Although the government's support is fundamental for the development of social work in China, Wang (2011) believes that the subordinate status of social work in the administrative system has hindered the impact of the new profession. Chinese social workers should advocate for their own status by creating new services that the government has not developed, such as medical social work, school social work, and mental health services. In this way, it will be easier for social workers to establish professional reputations. Also, hospitals and schools are secondary settings for social workers. They do not have to start from a blank slate or create activities to fulfill a schedule. Rather, they can work within a multi-disciplinary team with an independent role. In recent years, there have been urgent needs for interventions in doctor-patient and teacher-student relationships. It would be a good opportunity for social workers to contribute to the situation from their own perspectives.

For Chinese social work researchers, it is time to focus more on practical development. From the literature review, it was found that most authors wrote about social work on a macro level, such as policy analysis, academic programs, historical evolvement, and Chinese culture. However, few studies have been done on how to relate those macro-level issues to micro-level practice. Also, evidence-based practice is missing and there are barely any empirical studies. More needs assessments and program evaluations should be done to examine social problems and the effectiveness of existing services. With sufficient empirical studies, social workers can negotiate with the government to develop feasible plans for serving vulnerable populations.

For Chinese social work educators, it is essential to study how to incorporate Western social work values and methods into China's context. It is reasonable to suspect that some values will conflict with traditional Chinese values. Chinese social workers should not be judged if they do or do not adopt these Western values. Social work educators should never ignore the influences of the traditional Chinese culture and current political system on the development of social work profession. After the earthquake in 2008, social workers have gained much more public recognition because of their involvement 
in crisis intervention and post-traumatic intervention. Appropriate use of mass media is an effective way to gain public recognition. Chinese social workers should cooperate with the media to publicize this new profession and attract more people to participate in the professional team.

International cooperation is also imperative. Chinese social workers should critically consider the theories and practices from developed countries before using them. Shortterm condensed training programs could be provided to social work educators, and joint programs could be developed through collaboration at the university level. Social work educators and practitioners in developed countries should not impose Western values on Chinese colleagues, nor prescribe conclusive solutions to Chinese social problems (Chi, 2005).

\section{References}

Atinc, T. M., \& World Bank (1997). Sharing rising incomes: Disparities in China. Washington, DC: World Bank.

Bai, J., \& Daley, J. G. (2014). A snapshot of the current status of social work education in Mainland China. Journal of Social Work Education, 50, 525-534.

Chan, R. K. H., \& Tsui, M. S. (1997). Notions of the welfare state in China revisited. International Social Work, 40, 177-189.

Chi, I. (2005). Social work in China: Guest editorial for the special issue. International Social Work, 48(4), 371-379.

Chung, D. K. (1992). Asian cultural commonalities: A comparison with mainstream American culture. In S. M. Furuto, R. Biswas, D. K. Chung, K. Murase, \& F. RossSheriff (Eds.), Social work practice with Asian Americans (pp. 27-44). Newbury Park, CA: Sage Publications.

Gilbert, N. (2008). Welfare pluralism and social policy. In J. Midgley \& M. Livermore (Eds.), The handbook of social policy ( $2^{\text {nd }}$ ed., pp. 236-246). Los Angeles, CA: Sage Publications.

Guan, X. P. (2003). Social welfare reform in China. In P.W. Preston \& J. Haacke (Eds.), Contemporary China: The dynamics of change at the start of the new millennium (pp.113-126). London: RoutledgeCurzon.

Hung, S. L., Ng, S. L., \& Fung, K. K. (2010). Functions of social work supervision in Shenzhen: Insights from the cross-border supervision model. International Social Work, 53(3), 366-378.

Hutchings, A., \& Taylor, I. (2007). Defining the profession? Exploring an international definition of social work in the China context. International Journal of Social Welfare, 16, 382-390.

Jackson, R. (2011). Can an aging China be a rising China? China Business Review, April 2011, 32-59. 
Leung, J. C. B. (2001). Training social development cadres in China. Regional Development Dialogue, 22, 16-26.

Leung, J. C. B. (2007). An international definition of social work in China. International Journal of Social Welfare, 16, 391-397.

Leung, J. C. B., \& Nann, R. (1995). Authority and benevolence: Social welfare in China. Hong Kong: The Chinese University Press.

Leung, J. C. B., \& Wong, Y. C. (2002). Community-based service for the frail elderly in China. International Social Work, 45(2), 205-216.

Li, Y., Huang, C., \& Han, W. (2012). Development of social work education in China: Background, current status, and prospects. Journal of Social Work Education, 48(4), 635-653.

Lowe, G. (1995). Social development. In R. Edwards (Ed.-in-Chief), Encyclopedia of social work (19 ${ }^{\text {th }}$ ed., pp. 2168-2173). Washington, DC: NASW Press.

Midgley, J., \& Sherraden, M. (2008). The social development perspective in social policy. In J. Midgley, \& M. Livermore (Eds.), The handbook of social policy $\left(2^{\text {nd }}\right.$ ed., pp. 279-294). Los Angeles, CA: Sage Publications.

Ministry of Civil Affairs. (2008). Quarterly report on civil affairs ( $3^{\text {rd }}$ quarter in 2008). Retrieved from http://cws.mca.gov.cn/accessory/200810/1225069378523.htm

Mok, B. H. (1983). In the service of socialism: Social welfare in China. Social Work, 28(4), 269-272.

National Bureau of Statistics of the People's Republic of China. (2013). President's report. Retrieved from http://www.stats.gov.cn/

Sha, W., Wong, Y., Lou, V. W. Q., Pearson, V., \& Gu, D. (2012). Career preferences of social work students in Beijing and Shanghai. Social Work Education, 31(1), 4-21.

Shang, X., Wu, X., \& Wu, Y. (2005). Welfare provision for vulnerable children: The missing role of the state. The China Quarterly, 18, 122-136.

Shanghai Civil Affairs Bureau. (2010). The professionalization of social work in Shanghai. Retrieved from http://www.shmzj.gov.cn/gb/shmzj/node4/node13/node1488/userobjectlai28673.htm $\underline{1}$

Smith, A. E. (2003). Social work and ethnic minorities: Social development in the People's Republic of China. International Social Work, 46(3), 403-419.

Tang, K. L. (1996). The marginalization of social welfare in developing countries: The relevance of theories of social policy development. Journal of Sociology and Social Welfare, 23(1), 41-57.

Tong, M. (2007). Reflection on social work field education in Mainland China: A journey to become a professional social work educator. Social Work Education, 26(6), 645648. 
Tsang, A. K. T., \& Yan, M. C. (2001). Chinese corpus, western application: The Chinese strategy of engagement with western social work discourse. International Social Work, 44(4), 433-454.

Wang, S. B. (2011). The Embedded Model of social work development in China. Social Sciences Frontier, 2, (in Chinese).

Wong, L. (2008). The third sector and residential care for the elderly in China's transitional welfare economy. The Australia Journal of Public Administration, 67(1), 89-96.

Wong, Y., \& Pearson, V. (2007). Mission possible: Building social work professional identity through fieldwork placements in China. Social Work Education, 26(3), 292310.

Xiong, Y. G., \& Wang, S. B. (2007). Development of social work education in China in the context of new policy initiatives: Issues and challenges. Social Work Education, 26(6), 560-572.

Yan, M. C., \& Tsang, K. T. (2005). A snapshot on the development of social work education in China: A Dephi study. Social Work Education, 24, 883-901.

Yan, M. C., Ge, Z., Cheng, S., \& Tsang, A. K. T. (2009). Imagining social work: A qualitative study of students' perspectives on social work in China. Social Work Education, 28(5), 528-543.

Yuen-Tsang, W. K. A., \& Wang, S. B. (2002). Tensions confronting the development of social work education in China: Challenges and opportunities. International Social Work, 45, 375-388.

\section{Author note}

Address correspondence to: Jieru Bai, PhD, Assistant Professor, Grace Abbott School of Social Work, University of Nebraska at Omaha (UNO), 6001 Dodge Street, CB 205K, Omaha, NE 68182-0293. E-mail: jbai@unomaha.edu 